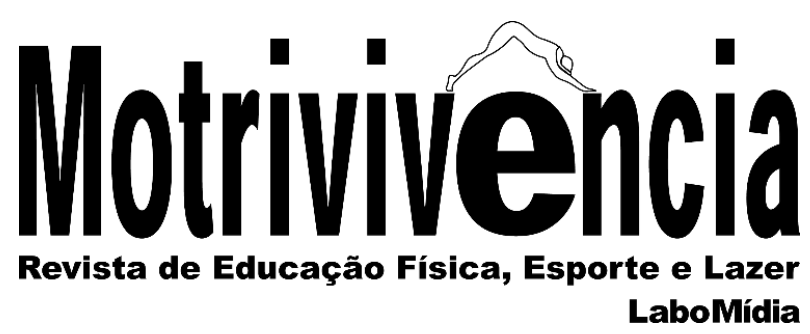

\title{
Os impactos da pandemia no exercício profissional de professores de dança em academias de Campo Grande (MS)
}

\section{RESUMO}

A pandemia provocada pela covid-19 afetou todo o mercado brasileiro de forma abrupta. A dança foi uma das áreas que obteve grande perda financeira e o presente artigo tem como objetivo avaliar o impacto na atuação de professores de dança em Campo Grande (MS) causado pelo covid-19. Tratase de um estudo quanti-qualitativo, em que foi disponibilizado um questionário on-line para 23 docentes. Para as perguntas quantitativas, realizouse uma análise descritiva dos dados, os quais serão apresentados em tabelas. Nas questões qualitativas o estudo compreendeu três etapas: organização e leitura dos documentos; codificação dos materiais e categorização. De maneira geral, a pandemia diminuiu a renda dos profissionais pesquisados, devido à suspensão das aulas e à redução na quantidade de alunos. Além disso, muitos foram forçados a mudar sua maneira de trabalhar e a buscar meios de complementação salarial, até mesmo por auxílios do governo.

PALAVRAS-CHAVE: Dança; Pandemia; Covid19; Mercado da dança

\section{Karen de Souza Cruz}

Zootecnista

Discente de Educação Física Licenciatura Universidade Federal de Mato Grosso do Sul, FAED, Campo Grande, Brasil kakascruz@gmail.com

${ }^{\circ}$ https://orcid.org/0000-0002-0136-2463

Marcelo Victor da Rosa

Doutor em Educação

Universidade Federal de Mato Grosso do Sul,

FAED, Campo Grande, Brasil marcelo.rosa@ufms.br

ํㅐttps://orcid.org/0000-0002-0621-0389 
The impacts of the pandemic on the professional activity of dance teachers in gyms in Campo Grande (MS)

\begin{abstract}
The pandemic caused by covid-19 affected the entire Brazilian market abruptly. The dance was one of the areas that obtained significant financial loss, and this article has the objective of evaluating the impact on teachers of dance performance in Campo Grande (MS) caused by covid-19. It is a quanti-qualitative study in which an online questionnaire was made available to 23 teachers. For the quantitative questions, a descriptive analysis of the data was carried out, which will be presented in tables, and concerning the qualitative questions, the study comprised three stages: organization and reading of documents; the codification of materials and categorization. In general, the pandemic has reduced the professionals' income due to the suspension of classes and the reduction in the number of students. In addition, many were forced to change their way of working and seek means to supplement their wages, even by government aid.
\end{abstract}

KEYWORDS: Dance; Pandemic; Covid-19; Dance market

Los impactos de la pandemia en el ejercicio profesional de los profesores en las academias de danza de Campo Grande (MS)

\title{
RESUMEN
}

La pandemia causada por el covid-19 afectó abruptamente a todo el mercado brasileño. La danza fue una de las áreas que tuvo grandes pérdidas financieras, y este artículo tiene como objetivo evaluar el impacto en el desempeño de los profesores de danza en Campo Grande (MS) causado por el covid-19. Se trata de un estudio cuantitativo y cualitativo, en el que se puso a disposición de 23 profesores un cuestionario en línea. En cuanto a las preguntas cuantitativas, se realizó un análisis descriptivo de los datos, que se presentará en gráficos y preguntas cualitativas. El estudio comprendió tres etapas: organización y lectura de documentos; codificación de materiales y categorización. En general, se percibió que la pandemia redujo los ingresos de los profesionales investigados debido a la suspensión de las clases y la reducción del número de estudiantes. Además, muchos se vieron obligados a cambiar su forma de trabajar y a buscar formas de complementar sus sueldos, incluso con ayuda del gobierno.

PALABRAS-CLAVE: Danza; Pandemia; Covid-19; Mercado de danza 


\section{INTRODUÇÃO}

A descoberta do novo coronavírus foi anunciada em 2019, na China, pela Organização Mundial de Saúde (OMS), que rapidamente avançou e se tornou uma pandemia ${ }^{1}$, forçando o mundo inteiro a tomar as providências cabíveis. A literatura nos traz que o SARS-CoV-2 é um vírus de RNA (Ácido Ribonucleico), causador de infecções respiratórias, entéricas, hepáticas e neurológicas em uma variedade de animais, incluindo aves e mamíferos (FEHR; PERLMAN, 2015). No referido ano foram relatados casos de pneumonia de causa desconhecida ocorridos em Wuhan, cidade chinesa. Em 9 de janeiro de 2020, a OMS confirmou a circulação do novo vírus. Em 30 de janeiro, declarou a epidemia uma emergência internacional (PHEIC) $)^{2}$. Ao final do mesmo mês, diversos países já haviam confirmado importações de casos, incluindo Estados Unidos, Canadá e Austrália.

No Brasil, em 7 de fevereiro, já havia nove situações em investigação, mas sem registros de casos confirmados ${ }^{3}$.Em poucos meses o mundo estava em uma situação pandêmica com um vírus que possui alta transmissibilidade e proporção de infectados oligossintomáticos e assintomáticos, estimada em mais de 30\% (NISHIURA et al., 2020). O Brasil pode observar atentamente as atitudes tomadas pelos outros países, o que resultou nas decisões que provocaram as medidas de isolamento social e que determinaram o funcionamento de apenas os serviços essenciais. Em 11 de março de 2020, a covid-19 foi declarada pela OMS como uma pandemia, conforme a Organização Panamericana de Saúde (OPAS, 2020).

Nesse cenário, a principal medida adotada foi a Lei n. ${ }^{0} 13.979$, de 6 de fevereiro de $2020^{4}$, que se refere às ações de saúde pública. Com alto potencial restritivo de direitos imprescindíveis, a norma adota inclusive a quarentena e o distanciamento social. Em contrapartida, a ação de combate a pandemia, a longo prazo, causa trágicos efeitos econômicos e sociais, devido ao fechamento dos setores considerados "não essenciais". Diante dessa realidade, diversos estabelecimentos tiveram suas portas fechadas - empresas, escolas, parques, dentre muitos outros - e o principal questionamento foi o mesmo: como agir nessa situação?

\footnotetext{
1 A primeira denominação adotada pela OMS foi "novo coronavírus 2019" (em inglês, "2019 novel coronavirus"), posteriormente alterada para SARS-CoV-2. Em 11 de fevereiro, a OMS passou a chamar a doença decorrente do vírus de "COVID-19", que é o acrônimo de "doença por coronavírus" ("coronavirus disease"), acrescido do ano relativo à aparição do surto (WHO, 2020).

${ }^{2}$ IHR procedures concerning public health emergencies of international concern (PHEIC) (WHO, 2015).

${ }^{3}$ Conforme informações da Secretaria de Vigilância em Saúde do Ministério da Saúde que traz dados sobre a infecção humana pelo novo coronavírus (2019-nCoV) em seu Boletim Epidemiológico 2020 (BRASIL, 2020b).

${ }^{4}$ Lei n. ${ }^{\circ} 13.979$, de 6 de fevereiro de 2020, dispõe sobre "as medidas para enfrentamento da emergência de saúde pública de importância internacional decorrente do coronavírus responsável pelo surto de 2019” (BRASIL, 2020a).
} 
O segmento informal é acompanhado pela vulnerabilidade, segundo os estudos de GirardNunes e Silva (2013). Por outro lado, algumas instituições conseguiram obter um melhor equilíbrio durante a crise, pois “[...] Por mais que empresas de grande porte também estejam passando por dificuldades com o coronavírus, elas possuem uma base estrutural maior para lidar com uma crise e arcar com um prejuízo" (MARINS; SHIBATTA, 2020).

Ao analisarmos o setor cultural é possível observar que ele já vinha sofrendo queda e desvalorização. Calabre (2020) entende que o Governo atual elegeu a cultura como inimiga, rejeitando as liberdades de criação e de expressão (sugerindo até mesmo a volta da censura) e pela deliberada intenção de asfixiá-la financeiramente. Outra adversidade diz respeito à modernização desse segmento. Maranhão (2019, p. 21) relata que:

No campo da cultura, as novas tecnologias digitais têm afetado a criação, disseminação e fruição de bens culturais, sobretudo por meio da internet, alterando substancialmente mercados já estabelecidos e, em alguns casos, criando formas de consumo e circulação de produtos.

Embora nos encontremos em um cenário pandêmico com a proibição das aglomerações, Calabre (2020, p. 11) assegura que "[...] a música, a dança, a arte em geral, foram ovacionadas como canais de escape fundamentais da solidão, como alento e esperança de tempos e vidas sãs". Assim, é possível refletir o quanto a utilização da tecnologia contribuiu para o consumo de produtos culturais, da valorização da cultura e do uso do tempo diário com atividades artísticas. Contudo, essa abordagem foi positiva para os profissionais da dança? De que forma eles poderiam utilizar essa tecnologia para exercer sua profissão? Em período de pandemia, como conseguem sobreviver? É imprescindível salientar que o docente é um dos principais pilares e mais importantes indivíduos no processo de ensino-aprendizagem, sendo o agente facilitador do acesso ao conhecimento pelos educandos, ajudando-lhes na apreensão dos saberes (PEDROZA; DIETZ, 2020). Então, como conseguir realizar o papel de professor de dança com a imposição do distanciamento social?

Sabe-se que a pandemia é um acontecimento que trouxe para todos os setores um alto índice de desemprego e, no mercado da dança, não foi diferente, com escolas fechadas, academias perderam vários alunos e eventos foram cancelados. O ano de 2020 se caracterizou pelo fechamento e pelas restrições dos serviços considerados não essenciais. Até o maior festival de dança do Brasil que acontece em Joinville (SC) foi adiado. Por isso, a pergunta: como manter a renda desse setor, uma vez que ele não é considerado essencial? Com todas as mudanças, dificuldades e possibilidades 
do atual cenário, este estudo tem como objetivo avaliar o impacto na atuação de professores de dança em Campo Grande (MS) causado pela covid-19.

\section{ASPECTOS METODOLÓGICOS}

Este estudo se configura como quanti-qualitativo, uma vez que segundo Souza e Kerbauy (2017, p. 37): “[...] a realidade é multifacetada e, como tal, não é superficial afirmar que dados gerados por métodos distintos podem ser agregados, na perspectiva de compreensão das várias faces da realidade". Por isso, é necessário um levantamento de dados mais concreto por lidar com situações e problemas reais e inovadores, os quais estão sujeitos a interpretações. A combinação de duas abordagens possibilita dois olhares diferentes e propicia uma visualização ampla da investigação.

Trata-se de uma pesquisa de campo que visa buscar informações com a população delimitada, por meio da aplicação de um questionário exploratório respondido por 23 professores de dança da cidade de Campo Grande (MS), atuantes em diversas vertentes. Todos concordaram com o Termo de Esclarecimento Livre e Esclarecido, presente no documento.

Foram elaboradas 25 questões para que os docentes pudessem responder diretamente pelo aplicativo Google Forms 5 . A busca pelos profissionais foi realizada a partir de mensagens nas redes sociais (whatsapp e instagram), por meio das páginas de escolas e academias de dança, bem como indicações de outros professores. Aqueles que se propuseram e aceitaram responder entraram no link da pesquisa, enviado previamente pela pesquisadora. O material esteve disponível para ser respondido durante 10 dias, período correspondente entre 10 e 20 de novembro de 2020. Com a finalidade de fazer um levantamento comparativo, as perguntas foram criadas a partir de três momentos: antes da pandemia; nos três primeiros meses com o lockdown decretado (ou seja, o bloqueio total das atividades) e no período atual.

Visando avaliar a eficácia do questionário foi feito um piloto que é definido como um instrumento em pequena escala capaz de reproduzir os meios e os métodos planejados para um dado estudo que serão encontrados no levantamento de dados definitivos (SILVA; OLIVEIRA, 2015). Para isso, uma profissional de dança foi convidada para participar, uma vez que esse tipo de trabalho científico deve preferencialmente ocorrer com uma população semelhante à da pesquisa definitiva (MACKEY; GASS, 2005).

\footnotetext{
${ }^{5} \mathrm{O}$ link de acesso para o questionário está disponível em: https://docs.google.com/forms/d/1qv61KOLzNxF02q6 NlGBriAYLnPNZqZG0ut3JP9DXCQc/edit.
} 
Nessa análise preliminar, cronometrou-se o tempo de duração e, posteriormente, foram expressas considerações sobre a ferramenta de análise. Dentre elas, apontou-se algumas sugestões ortográficas no texto do questionário e foi verificado que na questão sobre as vertentes ministradas (ballet, dança de salão, ritmos, dança de rua e jazz), alguns professores necessitavam marcar mais de uma opção e não havia como. Apesar de estar disponibilizada a opção "outro", na qual seria possível apontar uma nova vertente, a decisão foi de apenas modificar as informações da pergunta. Sobre os pontos positivos da referida pesquisa, a participante a considerou muito relevante e espera que possa produzir um bom material, pois trata-se de um assunto atual e até incerto, pois ninguém sabe até quando a pandemia irá durar. Um exemplo é que, novamente, estamos vivendo um aumento no número de casos ${ }^{6}$.

Vale destacar que o estudo científico foi elaborado de acordo com cada tipo de pergunta abertas e fechadas. As respostas das questões fechadas foram avaliadas a partir de uma análise descritiva e os dados apresentados em tabelas. As respostas dos questionamentos abertos foram examinadas por meio do método de Bogdan e Biken (1994 apud FARIAS et al., 2020), compreendendo os elementos qualitativos em três etapas. Segundo Farias et al. (2020), a primeira fase consiste na organização e leitura dos documentos. Desse modo, foram colocadas as perguntas e as respostas em um documento do aplicativo Word e estudadas uma a uma. Em seguida, iniciou-se a codificação, que consiste em identificar trechos, recortes de falas, palavras, ideias repetidas, comportamentos, isto é, interpretar os significados contidos nos diversos documentos da amostra (FARIAS et al., 2020).

As respostas que se assemelhavam foram selecionadas com uma mesma cor gerando uma codificação. Por fim, a última etapa da análise dos dados consiste na categorização. Assim, organizou-se as informações considerando a sintonia estabelecida entre elas (FARIAS, et. al., 2020). Por exemplo, na primeira pergunta aberta, obteve-se duas categorias (desvalorização e promissor) e, na segunda, foram quatro (tecnologia, espaço, motivação e trabalho).

\section{CONCEPÇÕES DOCENTES SOBRE A DANÇA NO CONTEXTO PANDÊMICO}

É fato que o setor da dança sofre uma desvalorização, apesar do seu crescimento e o desenvolvimento dos profissionais que ainda lutam por condições de trabalho e salários justos e neste momento de crise mundial não foi diferente. A presente pesquisa mostrou o que está

\footnotetext{
${ }^{6}$ Boletim epidemiológico do coronavírus - casos em Mato Grosso do Sul, do dia 18 de dezembro de 2020 (MATO GROSSO DO SUL, 2020a).
} 
acontecendo nesse nicho de mercado em Campo Grande, sendo possível estabelecer o perfil desses trabalhadores. Contatou-se que entre os partícipes a média obtida das idades dos professores é de 28 anos: 20, a menor e 39, a maior idade. Partindo para uma discussão do período de atuação, a média obtida dos anos que atuam como professores de dança é de 6,7 anos, sendo 2 anos o menor período de experiência e 15 anos o maior tempo de atuação. Podemos concluir que os profissionais pesquisados possuem uma vasta experiência docente, o que é muito importante, pois “[...] a experiência da dança em sala de aula provoca o sujeito na sua totalidade em cada vivência" (MILLER, 2014, p. 106). É possível observar que muitos começaram a ministrar aulas por volta dos 20 ou 22 anos. Isso se dá devido ao artista de tal expressão artística procurar por estudos em cursos livres em estúdios, academias ou escolas de dança, caracterizado como ensino informal (CAMARGO, 2008 apud SIQUEIRA et. al., 2016).

Ao serem interrogados sobre a identidade de gênero, a maioria respondeu que se considera mulher cis e apenas um se identifica como não binário. Porém, apesar da explicação contida na pergunta sobre cisgênero e transgênero ${ }^{7}$, um participante respondeu que era "hétero", desse modo o colocamos na opção homem cis, no que resultou em 10 pessoas nessa opção. Quando falamos de identidade de gênero precisamos saber que "[...] homem ou mulher não são os cromossomos ou a conformação genital, mas a autopercepção e a forma como a pessoa se expressa socialmente" (JESUS, 2012, p. 8).

A seguir são apresentados os dados obtidos com as respostas do questionário e que abordam questões como: formação; vertentes ministradas; quantidade de academias em que os profissionais trabalham; número de turmas e de alunos que participam das aulas e a situação salarial.

Tabela 1 - Formação profissional dos professores de dança

\begin{tabular}{c|c}
\hline Grau de escolaridade & $\begin{array}{c}\text { Quantidade } \\
\text { de professores }\end{array}$ \\
\hline Ensino Superior Incompleto & 8 \\
\hline Ensino Superior Completo & 6 \\
\hline Especialização Completa & 5 \\
\hline Ensino Médio Completo & 2 \\
\hline
\end{tabular}

7 Cisgênero é o indivíduo que se identifica com o sexo biológico (masculino ou feminino) com o qual nasceu. Transgênero é a pessoa que se identifica com um gênero diferente daquele que lhe foi dado no nascimento. 


\begin{tabular}{c|c}
\hline Mestrado Completo & 1 \\
\hline Ensino Médio Incompleto & 1 \\
\hline
\end{tabular}

Fonte: elaborada pelos autores.

Conforme a Tabela 1, o grau de escolaridade é considerado alto, apesar de que a opção mais citada ser a de Ensino Superior Incompleto ( 8 professores) e mais da metade dos entrevistados possuírem uma graduação; alguns contam com especialização e mestrado, o que aponta um crescimento pela formação contínua. Não é possível dizer que todos os profissionais são formados em dança, pois em Campo Grande há apenas um curso na Universidade Estadual de Mato Grosso do Sul (UEMS), intitulado “Teatro e Dança". Aliás, como bem salienta Ehrenberg (2003), apesar de possuir sua própria graduação, a Dança é compartilhada pela Educação Física e por outras áreas do conhecimento.

Na presente pesquisa, obtivemos o seguinte perfil: a predominância na área é de mulheres cis, com média de 28 anos, com experiência como docente de dança há, aproximadamente, 6 anos.

Com relação às vertentes ministradas, os participantes puderam assinalar ou escrever mais de uma opção. Percebeu-se que a maioria ministra aula em mais de uma área. $\mathrm{O}$ ballet, a dança de salão e os ritmos foram os mais citados. Diante disso, o questionamento que fazemos é: esses estilos, consequentemente, são os mais procurados na cidade? O ballet é ensinado por 8 dos 23 professores pesquisados. Podemos entender a popularização entre os partícipes por essa ser uma das manifestações mais antigas da dança e seus benefícios são conhecidos pela população. Moreira (2014, p. 87), explica:

O balé ainda é visto por muitos como uma disciplina física completa. Em seu exercício contínuo, trabalham-se força, resistência, postura, equilíbrio, alongamento, flexibilidade, graciosidade e elegância. Além dos inúmeros benefícios físicos, sociais e mentais que estão associados à prática dessa técnica, comprova-se sua eficácia para quem pratica outros gêneros de dança: danças de salão, dança contemporânea, danças urbanas etc.

Vale ressaltar que enquanto o crescimento da prática do ballet se deu com a tradição, a dança de salão teve mais visibilidade por meio da mídia. Na segunda expressão artística ocorre uma mistura de diversos ritmos e sua riqueza está na possibilidade de privilegiar diversas formas de trabalho, nos quais estilos, técnicas e tendências são permanentemente influenciados pelas tradições, símbolos e valores culturais de cada povo (ALMEIDA, 2005). 
O terceiro item mais citado é uma vertente a qual a sua busca tem finalidades específicas queima de calorias, tonificação dos músculos, melhora no condicionamento físico e na coordenação motora de uma forma dinâmica e muito divertida (ARSEGO, 2012). A aula de ritmos é praticada por aqueles que procuram uma atividade que utiliza vários tipos de músicas, estilos e coreografias, bem como tenha uma duração de 45 a 60 minutos. Existem várias dimensões que motivam a prática da dança em academias, "disposto ao agrado de cada aluno que almeja frequentá-las" (COSTA et al., 2018).

Porém, todo o crescimento desse mercado se viu ameaçado com a chegada da pandemia e a publicação do Decreto n. ${ }^{\circ} 14.189^{8}$, de 15 de março de 2020, no Diário Oficial de Campo Grande (Diogrande) e a suspensão das atividades consideradas não essenciais, abarcando as academias. Por isso questionamos: como tais empresas agiram em meio a essas medidas? Em nosso estudo, quando perguntados sobre a primeira atitude tomada pelas academias onde ministravam as aulas, a maioria dos professores (13) respondeu que elas tiveram suas portas fechadas, mas que poderiam continuar o trabalho oferecendo aulas on-line. O restante (10) declarou que os estabelecimentos encerraram suas atividades e dispensaram os alunos.

Partindo para a análise das aulas remotas, a opção mais citada pelos docentes (7) foi que menos de $50 \%$ dos discentes aderiram à referida modalidade de ensino, sendo que 6 professores informaram que apenas metade da turma participou efetivamente. Em 16 de abril de 2020, a prefeitura municipal liberou a abertura das academias e, por conta disso, foi montado um protocolo de segurança e de normas seguindo as orientações da OMS, para que as atividades pudessem ser retomadas. Os proprietários, bem como os professores precisaram reformular o espaço e adequar suas aulas para o retorno dos alunos.

Tabela 2 - Quantidade de academias trabalhadas

\begin{tabular}{c|c|c|c}
\hline \multicolumn{2}{c|}{ Antes da pandemia } & \multicolumn{2}{c}{ Durante a pandemia } \\
\hline $\begin{array}{c}\text { Número } \\
\text { de academias }\end{array}$ & $\begin{array}{c}\text { Quantidade } \\
\text { de professores }\end{array}$ & Número de academias & $\begin{array}{c}\text { Quantidade } \\
\text { de professores }\end{array}$ \\
\hline Uma & 14 & Uma & 14 \\
\hline Duas & 5 & Duas & 6 \\
\hline Três & 4 & Três & 1 \\
\hline
\end{tabular}

${ }^{8}$ Dispõe sobre as medidas para enfrentamento da emergência de saúde pública de importância internacional decorrente do Novo Coronavírus - COVID-19 e dá outras providências (MATO GROSSO DO SUL, 2020b). 


\begin{tabular}{c|c|c|c}
\hline Nenhuma & 0 & Nenhuma & 2 \\
\hline
\end{tabular}

Fonte: elaborada pelos autores.

$\mathrm{Na}$ Tabela 2, observamos que antes da atual crise de saúde mundial todos estavam empregados e a maioria atuava em apenas um local (14). Durante a pandemia, nos três últimos meses de 2020, observamos que permaneceu a quantidade de professores que trabalham em apenas uma instituição. Apenas um dos partícipes está em três academias diferentes. Notamos também que aumentou para 6 o número de educadores realizando atividades em duas academias e 2 deles não estão ministrando aulas.

Consequentemente, o fechamento das academias refletiu também na quantidade de turmas. Antes da pandemia apenas 4 professores ministravam aula em apenas uma, 6 deles lecionavam em duas e outros 6 profissionais possuíam mais de 5. Durante a pandemia 5 educadores contam com um grupo de alunos; diminuiu para 4 o número de instrutores que ensinam para duas turmas e aumentou para 5 aqueles com três. Dois dos participantes estão apenas com aulas particulares e 4 não têm turma.

Tabela 3 - Número de alunos por turma

\begin{tabular}{c|c|c|c}
\hline \multicolumn{2}{c|}{ Antes da pandemia } & \multicolumn{2}{c}{ Durante a pandemia } \\
\hline Número de alunos & $\begin{array}{c}\text { Quantidade de } \\
\text { professores }\end{array}$ & Número de alunos & $\begin{array}{c}\text { Quantidade de } \\
\text { professores }\end{array}$ \\
\hline $5-10$ & 9 & Até 5 & 8 \\
\hline $10-15$ & 9 & $5-10$ & 5 \\
\hline Até 5 & 2 & $10-15$ & 3 \\
\hline Mais de 20 & 2 & Sem resposta & 2 \\
\hline $15-20$ & 1 & $15-20$ & 1 \\
\hline
\end{tabular}

Fonte: elaborada pelos autores.

É possível observar na Tabela 3 que antes a maioria das turmas de dança tinha entre 5-10 e 10-15 alunos. Durante a pandemia houve uma diminuição na quantidade, sendo que dos partícipes 
deste estudo, 8 docentes mencionaram que possuem turmas com até 5 discentes e 3 não responderam essa questão. Do total de 22 professores entrevistados, 19 voltaram a ministrar aulas presenciais.

Tabela 4 - Valor salarial dos profissionais de dança

\begin{tabular}{c|c|c|c|c|c}
\hline \multicolumn{3}{c|}{ Antes da pandemia } & \multicolumn{3}{c}{ Durante a pandemia } \\
\hline$<$ Valor & Média & $>$ Valor & $<$ Valor & Média & $>$ Valor \\
\hline $\mathrm{R} \$ 0$ (voluntário) & $\mathrm{R} \$ 1.768,26$ & $\mathrm{R} \$ 4.500,00$ & $\mathrm{R} \$ 0$ & $\mathrm{R} \$ 1.180,00$ & $\mathrm{R} \$ 4.500,00$ \\
\hline
\end{tabular}

Fonte: elaborada pelos autores.

A Tabela 4 mostra que a média salarial dos professores que participaram da pesquisa, antes da pandemia, era de $\mathrm{R} \$ 1.768,26$ e o maior valor citado foi de $\mathrm{R} \$ 4.500,00$. No caso da identificação de R $\$ 0,00$, o entrevistado atuava como voluntário. Quando perguntamos sobre o salário durante a pandemia, 2 professores não responderam. $\mathrm{O}$ valor pago aos docentes nesse período foi menor em relação aos meses anteriores, ou seja, caiu para $\mathrm{R} \$ 1.180,00$. O maior valor citado foi o mesmo de antes da pandemia e o menor valor também, porém na época em que foi aplicada a pesquisa, a atuação voluntária foi mencionada por 3 docentes.

Tabela 5 - Situação salarial no lockdown

\begin{tabular}{c|c}
\hline Salário no lockdown & Quantidade de professores \\
\hline Diminuiu & 11 \\
\hline Não diminuiu & 5 \\
\hline Não obteve salário & 5 \\
\hline Não responderam & 2 \\
\hline
\end{tabular}

Fonte: elaborada pelos autores.

Entendemos que a queda na situação salarial (Tabela 5) pode ser devido ao corte nos proventos, como mencionado por 11 professores, sendo que 5 profissionais não obtiveram seu salário e 2 não responderam a pergunta. Com a diminuição ou perda da renda mensal dos profissionais em todos os setores, não só no da dança, causado pelo distanciamento social, a 
principal política pública federal para tentar minimizar os efeitos sociais foi a criação do auxílio emergencial instituído pela Lei n. ${ }^{0} 13.982$, de $2020^{9}$, com intuito de proteção social aos chamados trabalhadores informais, desde que atendidas as condições estipuladas na referida determinação.

Quando questionados sobre os subsídios que poderiam ter adquirido durante a pandemia, 11 docentes disseram que receberam o referido auxílio, 1 respondeu que conseguiu o valor referente ao projeto emergencial MS Cultura Presente ${ }^{10}$ e outros 11 não tiveram acesso a nenhum subsídio governamental. Nesse último caso, não sabemos se por falta de interesse ou por não se encaixarem nas condições estipuladas pela Lei. Com a suspensão de todas as atividades artísticas e culturais e da falta de qualquer perspectiva de retorno, parte do setor cultural começou a se mobilizar em busca da garantia do apoio do Estado, nos diversos níveis de governo (CALABRE, 2020).

Alguns governos estaduais e municipais implementaram ações variadas. No estado sulmato-grossense, por exemplo, foi lançado o edital MS Cultura Presente, da Fundação de Cultura do Mato Grosso do Sul (FCMS), no qual apenas um professor da presente pesquisa foi beneficiado. Ainda era necessária uma ajuda mais concreta para esse setor em nível nacional, tanto que:

O Fórum Nacional de Secretários e Dirigentes Estaduais de Cultura, o Fórum de Conselhos Estaduais e Municipais de Cultura, a Rede Nacional de Pontos e Pontões de Cultura, entre outros, iniciaram um intenso diálogo com os parlamentares em busca de medidas legais que garantem um nível mínimo de renda que permitisse a sobrevivência aos tempos de pandemia (CALABRE, 2020, p. 15).

Então, foi criada a Lei de Emergência Cultural Aldir Blanc ${ }^{11}$. Ao analisar os profissionais de dança em Campo Grande que realizaram a inscrição para serem beneficiados, observamos um resultado semelhante se comparado com a procura do auxílio emergencial. Não obtivemos resposta de apenas um participante nessa questão e dos entrevistados, 11 professores se inscreveram para os editais. Uma pessoa se inscreveu no do auxílio aos artistas e o restante para o "Prêmio Sul-MatoGrossense de Dança - Lei Aldir Blanc”, em que 7 dos 10 inscritos foram selecionados. Ao contrário do subsídio oferecido pelo Governo Federal, a referida Lei teve uma menor divulgação, porém podemos perceber que a procura por receber esse direito foi satisfatória.

\footnotetext{
${ }^{9} \mathrm{O}$ auxílio emergencial criado pela referida Lei é um misto entre a Renda Básica de Cidadania, criada pela Lei n. ${ }^{\circ}$ 10.835, de 2004 e o Programa do Seguro-Desemprego, instituído pela Lei n. ${ }^{\text {0 } 7.998, ~ d e ~} 1990$ (CARDOSO, 2020).

10 “O edital visa a contratação de artistas naturais de Mato Grosso do Sul ou não, mas desde que residentes neste Estado há pelo menos 2 (dois) anos, maiores de idade, e que vivam exclusivamente de sua arte, para se apresentarem, exibirem suas obras, realizarem exposições e/ou ministrar oficinas, e que no período de isolamento social, determinado pelas autoridades públicas, não têm outra fonte de renda além daquelas advindas de seus trabalhos e produções na área artístico-cultural" (MATO GROSSO DO SUL, 2020).

${ }^{11}$ A Lei de Emergência Cultural Aldir Blanc (Lei n. ${ }^{\circ}$ 14.017/2020), recebeu esse nome em homenagem ao compositor, poeta, crítico social e músico, vitimado pelo novo coronavírus. Dispõe sobre as ações emergenciais para garantir renda aos profissionais e trabalhadores da cultura durante o período da pandemia.
} 
Partindo para a análise das questões abertas presentes no questionário, quando perguntados sobre a opinião em relação ao mercado de trabalho da dança na atualidade, obtivemos duas categorias de respostas: desvalorização e promissor. A primeira está pautada, principalmente, na dificuldade enfrentada pelos profissionais no tempo da pandemia, o que constatamos na fala do professor 6: “[...] Muito difícil. A pandemia nos atingiu de uma forma muito brusca, muitos professores que conheço de dança perderam todas as suas aulas e estão tendo que procurar outros meios de se sustentarem".

A pandemia do coronavírus atingiu todos os setores de forma brusca. Uma pesquisa do Serviço Brasileiro de Apoio às Micro e Pequenas Empresas revela que em apenas 15 dias (entre os meses de março e abril de 2020) as micro e pequenas empresas já teriam demitido 9,3 milhões de trabalhadores em todo o Brasil (SEBRAE, 2020). O impacto negativo causado no mercado financeiro brasileiro foi muito visível no setor cultural. Para Barbosa et al. (2020), o isolamento social levou à drástica, senão à completa redução dos dispêndios das famílias com “[...] cultura fora do lar, atividades como espetáculos, cinemas, teatros, shows, dança, em museus e afins tiveram sua demanda interrompida".

Em outra questão aberta do questionário, na categoria "promissor", podemos destacar um mercado que luta para se adequar à realidade em que se encontra, diante da qual foram desenvolvidas diversas estratégias para dar continuidade à prática da dança. A educação, na atualidade, foi modificada pela adaptação docente e discente a partir do uso de diversos programas, aplicativos, ferramentas que passaram a estar presentes (PASINI et al., 2020). De imediato, a dança vai por esse caminho também. Diante disso, podemos analisar o comentário do professor 8: “[...] Mais flexível e adaptável em relação a outras atividades. Mas depende muito da modalidade e do público também".

Segundo Terra (2009), o profissional da cultura sempre está em busca de novos arranjos para a produção e circulação das obras, além de outras formas de associação para a criação e produção artística. É uma maneira de enfrentar as questões econômicas que surgem. Na resposta do professor 2 podemos observar outros problemas enfrentados por eles, não apenas na atualidade.

Um completo descaso por meio do poder público e uma educação em arte inexistente no nosso sistema de ensino. Os governantes não priorizam a cultura, pois não entendem sobre o que ela realmente se trata. E não entendem justamente, porque não há uma educação que fale sobre arte de cultura de forma consistente na educação básica nem de forma teórica nem de forma prática.

O anseio por uma valorização do mercado cultural junto ao Poder Público data do século XX, cujos profissionais lutam pela "[...] elaboração de políticas, ou seja, uma preocupação dos 
governantes na preparação e realização de ações de maior alcance, com um caráter perene" (CALABRE, 2007). Governo após governo tentam serem ouvidos para melhorar o mercado de trabalho que, em sua maioria, é informal. No atual Governo Federal podemos observar várias ações que afetaram diretamente este setor. Sobre esse assunto, Calabre (2020, p. 11) relata que:

O novo governo bloqueou ou descontinuou inúmeras ações que eram realizadas com recursos próprios do governo federal através de editais e parcerias, com estados e municípios, tanto os do antigo Ministério da Cultura, quanto os da Fundação Nacional de Artes (Funarte) e de outras instituições vinculadas. Recomendou, ainda, que as estatais, como a Petrobrás, deixassem de ser patrocinadoras de eventos e atividades artísticas.

A falta de informação sobre as artes e a cultura, a escassez de docentes que consigam trabalhar na Educação Básica e que possam ensinar a respeito da importância desse contexto para os alunos, demonstram que o futuro dessas áreas ainda continua incerto, pois, acreditamos que uma formação abrangente do aspecto cultural é eminente para sociedade. "Apesar do crescimento da área de Dança, e do amplo reconhecimento da importância da Dança na cultura brasileira, faltam ainda no país centros superiores de ensino e pesquisa desta arte" (UNICAMP, 2006 apud BRASILEIRO, 2010, p. 37).

Dando procedência às análises qualitativas, os entrevistados foram indagados sobre a principal dificuldade enfrentada nessa pandemia em relação a questão profissional. As respostas nos proporcionaram inferir quatro categorias: tecnologia, espaço, motivação e trabalho. Diante da situação de isolamento, os instrutores foram impedidos de ministrar aulas presenciais de dança e muitos partiram para a modalidades on-line, solução imediata encontrada. Contudo, tal solução foi apontada como uma grande dificuldade, o que podemos observar nas palavras do professor 4: "[...] Inicialmente, a tecnologia, tanto para o professor quanto para os alunos ajudou a manter as atividades, porém não havia muito conhecimento das partes que aprenderam no decorrer do tempo".

A pandemia e o distanciamento social evidenciaram o quão importante é o uso das ferramentas tecnológicas, porém foi necessário adaptação e ao mesmo tempo saber conviver com este novo mundo. Nos deparamos com um país no qual alguns entendem de tecnologias e muitos ainda só sabem o básico.

A grande questão reside em como lidar com a exclusão digital existente no país como o Brasil, que conta com altos índices de pobreza e analfabetismo. É certo que a pobreza e o analfabetismo se constituem como problemas que precisam ser sanados com urgência. Mesmo assim, não há como pensar a exclusão digital em segundo plano, visto que o desenvolvimento das tecnologias se dá cada vez mais 
rapidamente e o abismo existente entre incluídos e excluídos tende a aumentar (LEMOS, 2007 apud ALONSO et al., 2010, p. 16).

Para que os alunos pudessem manter suas atividades foi necessário alterar o seu ambiente de aula para um local apropriado, boa conexão com a internet, orientação clara e bastante cuidado (ZIKAN et al., 2020). O que nos remete a pensar na segunda categoria obtida com a pesquisa: o espaço. Nas aulas on-line os professores encontraram dificuldades com o espaço de imediato e ao voltar para as presenciais isso só se agravou com as normas de biossegurança, como podemos perceber nas palavras do professor 5: “[...] Ainda há o medo de como lidar com os alunos e manter a proteção para ambos. Algumas academias na maior parte delas não têm espaços suficientes para manter certa distância". Para atividades que exigem ambientes físicos fechados deve ser determinado o limite de praticantes, levando em conta as peculiaridades de cada local, tais como ventilação, distanciamento e atividades propostas (CORTEZ et al., 2020).

Quando perguntados sobre a principal dificuldade enfrentada, encontramos a terceira categoria: a motivação. Em sua fala, o professor 7 relata: “[...] A frequência de alunos, pois estes vão se sentindo desestimulados em função de como as aulas têm que funcionar nesse período". São diversos os motivos de evasão em relação às aulas on-line. Dificuldade com as plataformas, o local e até mesmo horários, além do que, como Barbosa et al. (2020) relatam, vários discentes não possuem condições de arcar com equipamentos ou conexão com internet de banda larga. Nas aulas presenciais, os fatores de evasão vão desde a diminuição na quantidade dos alunos para manter o distanciamento, a rejeição do uso das máscaras durante a atividade física, o medo do contágio da doença durante a permanência do indivíduo no estabelecimento até o grande número de desempregados nos diversos setores. Essa problemática também contribuiu para que alguns profissionais não voltassem para o mercado de trabalho e os que possuíam uma renda extra relacionada à cultura obtivessem um prejuízo ainda maior.

A quarta categoria diz justamente do trabalho. Com a suspensão de eventos, esses profissionais acabaram ficando sem saída, o que conferimos no depoimento do professor 10 sobre os prejuízos financeiros: “[...] perdemos muito trabalho e eu dançava em shows também, está tudo parado!”. Ademais, as culturas e as artes se encontram em caminhos ainda desconhecidos e incertos. Córdula (2020 apud CORÁ, 2020, p. 323) afirma que: “ O setor cultural ocupava, em 2018, mais de 5 milhões de pessoas, de acordo com dados da Pesquisa Nacional por Amostra de Domicílios Contínua (PNAD Contínua), representando $5,7 \%$ do total de ocupados no país e movimentando R 226 bilhões em 2017.” 
A pandemia agravou várias áreas e o setor da dança, que sempre buscou reconhecimento, também foi afetado. Apesar de tudo, o profissional da dança se mostra persistente e esperançoso quanto ao seu futuro e contra toda a dificuldade, continua se adaptando e ressignificando cada obstáculo que enfrenta. Eles descobriram uma nova forma de educação, a on-line. Grandes eventos passaram a acontecer de maneira remota, surgindo, assim, o crescimento de um novo mercado. Com isso, observa-se que há uma tendência para a hiperconectividade, hiperprodução e hipercirculação das dinâmicas culturais em formato virtual e com aproximação de aparatos tecnológicos que suportam essas mudanças (CORÁ, 2020).

\section{CONSIDERAÇÕES FINAIS}

O presente artigo buscou evidenciar o impacto causado pela pandemia provocada pela covid-19, na atuação profissional de professores de dança em Campo Grande (MS). Por meio de um questionário aplicado aos docentes da área identificamos as principais consequências causadas ao referido mercado. O setor da cultura já sofria uma desvalorização diante do Governo Federal e a pandemia agravou ainda mais a situação desse nicho. Esses trabalhadores tiveram uma diminuição no número de turmas e de academias trabalhadas, o que atingiu diretamente sua renda mensal.

As normas de biossegurança e a desmotivação dos discentes acarretou uma diminuição na quantidade de alunos que, segundo o estudo, a opção mais respondida foi que as turmas possuíssem até 5 indivíduos. A maioria dos professores voltou a ministrar aulas presenciais, porém a dificuldade de resgatá-los é grande, devido ao medo do vírus, ao uso das máscaras que incomodam muito os praticantes, à desmotivação por conta das salas vazias e até pela questão financeira já que a economia está afetada.

Nas análises, podemos observar que antes da pandemia todos possuíam turmas de aulas de dança e, agora, vários são os professores que não têm. Os entrevistados relataram em suas falas as principais adversidades enfrentadas: as aulas on-line, a dificuldade de encontrar academias onde possam ministrar aulas para poucas pessoas, a desmotivação dos próprios alunos e a questão financeira.

O mercado da dança vinha lutando por sua valorização ao longo dos anos, porém pouco ainda é estudado e evidenciado. Isso nos remete a um dos limites encontrados na pesquisa, que é a falta do referencial teórico, tanto em relação ao referido mercado, quanto à pandemia do novo coronavírus. Vale ressaltar que devido ao distanciamento social vivenciado, enfrentamos alguns desafios, especialmente, quanto a abordagem dos profissionais. Por isso, a aplicação do questionário 
se deu via internet. No total foram contatados 34 docentes, porém apenas 23 responderam nossa solicitação e participaram desta investigação.

O momento atual revela que a pandemia está sofrendo sua segunda onda, o que pode abalar ainda mais o mercado da dança e da cultura. Evidenciamos, porém, que ainda existem lacunas a serem preenchidas, como a questão salarial desses professores, na atual conjuntura e não apenas no Brasil. Por isso, há a necessidade de pesquisas futuras para compreender o impacto causado no referido mercado.

\section{REFERÊNCIAS}

ALMEIDA, Cleuza Maria. Um olhar sobre a prática da dança de salão. Movimento \& Percepção, Espírito Santo de Pinhal, v. 5, n. 6, jan./jun., 2005.

ALONSO, Luiza Beth Nunes; FERNEDA, Edilson; SANTANA, Gislane Pereira. Inclusão digital e inclusão social: contribuições teóricas e metodológicas. Barbarói, Santa Cruz do Sul. p. 154-177, 2010.

ARSEGO, Nígia. Motivação à prática regular de atividades físicas nas academias de ginástica: uma revisão de literatura. 2012. 61f. Monografia (Bacharelado em Educação Física) - Universidade Federal do Rio Grande do Sul, Porto Alegre, 2012.

BARBOSA, Andre Machado; VIEGAS, Marco Antônio Serra; BATISTA, Regina Lucia Napolitano Felício Felix. Aulas presenciais em tempos de pandemia: relatos de experiências de professores do nível superior sobre as aulas remotas. Revista Augustus, Rio de Janeiro, v. 25, p. 255-280, 2020.

BRASIL. Folha informativa COVID-19 - Escritório da OPAS e da OMS no Brasil. Organização PanAmericana de Saúde (OPAS). Brasília, 2018. Disponível em: https://www. paho.org/pt/covid19. Acesso em: 20 out. 2020.

BRASIL. Lei n. ${ }^{\circ} 13.979$, de 6 de fevereiro de 2020. Dispõe sobre as medidas para enfrentamento da emergência de saúde pública de importância internacional decorrente do coronavírus responsável pelo surto de 2019. 27. ed. Diário Oficial da União, Brasília, seção 1, p. 1, 2020a. Disponível em: http://www.planalto.gov.br/ccivil 03/ ato2019-2022/2020/lei/11

3979.htm. Acesso em: 28 ago. 2020.

BRASIL, Boletim Epidemiológico: infecção humana pelo novo coronavírus (2019-nCoV). Secretaria de Vigilância em Saúde. Ministério da Saúde. Brasília, n. 2, 2020 b.

BRASILEIRO, Lívia Tenório. A dança é uma manifestação artística que tem presença marcante na cultura popular brasileira. Pro-Posições, Campinas, v. 21, n. 3, p. 135-153, 2010.

CALABRE, Lia. Políticas Culturais no Brasil: balanço e perspectivas. In: III ENECULT - Encontro de Estudos Multidisciplinares em Cultura, 2007, Salvador. Anais [...]. Bahia: Faculdade de Comunicação. Universidade Federal da Bahia (UFBA). Disponível em: http://rubi.casaruibarbosa.gov.br/bitstream/fcrb/451/2/Calabre,\%20L.\%20-\%20Politicas\%20

Culturais\%20no\%20Brasil. Acesso em: 15 nov. 2020.

CALABRE, Lia. A arte e a cultura em tempos de pandemia. Revista Extraprensa, São Paulo, v. 13, n. 2, p. 7-21, 2020. 
CARDOSO, Bruno Baranda. A implementação do Auxílio Emergencial como medida excepcional de proteção social. Revista de Administração Pública, Rio de Janeiro, v. 54, n. 4, 2020.

CONFEF. Conselho Federal de Educação Física. Intervenção do profissional de Educação Física. Resolução do CONFEF 046/2002. Rio de Janeiro, 2002.

CORÁ, Maria Amélia Jundurian. Reflexões acerca das Culturas e das Artes em Tempo de Pandemia. NAU Social, Bahia, v. 11, n. 21, p. 321-329, 2020.

CORTEZ, Antonio Carlos Leal; PITANGA, Francisco José Gondim; ALMEIDA-SANTOS, Marcos Antonio; NUNES, Rodolfo Alkmim Moreira; BOTERO-ROSAS, Daniel Alfonso; DANTAS, Estélio Henrique Martin. Centros de atividades físicas e promoção de saúde durante a pandemia da covid-19. Disponível em: https://preprints.scielo.org/index.php/ scielo/preprint/view/996/1415. Acesso em: 20 nov. 2020.

COSTA, Valdeir Farias da; MOURA, Stephanney Karolinne Mercer Souza Freitas; LOPES, Diego Trindade. Estudo da Demanda pela prática de dança aeróbica em academias. Revista Campo do Saber, Cabedelo, v. 4, n. 1, 2018.

EHRENBERG, Mônica Caldas. A Dança como conhecimento a ser tratado pela Educação Física escolar: aproximações entre formação e atuação profissional. Dissertação (Mestrado) - Faculdade de Educação Física, Universidade de Campinas (UNICAMP), Campinas, 2003.

FARIAS, Alison Nascimento; IMPOLCETTO, Fernanda Moreto; BENITES, Larissa Cerignoni. A análise de dados qualitativos em um estudo sobre educação física escolar: o processo de codificação e categorização. Pensar a Prática, Goiânia, v. 23, 2020.

FEHR, Anthony; PERLMAN, Stanley. Coronaviruses: an overview of their replication and pathogenesis. In: Coronaviruses. Humana Press, New York, p.1-23. 2015.

GIRARD-NUNES, Christiane; SILVA, Pedro Henrique Isaac. Entre o prescrito e o real: o papel da subjetividade na efetivação dos direitos das empregadas domésticas no Brasil. Sociedade e Estado, Brasília, v. 28, n. 3, p. $587-606,2013$.

JESUS, Jaqueline Gomes de. Guia técnico sobre pessoas transexuais, travestis e demais transgêneros, para formadores de opinião. 2. ed. Orientações sobre identidade de gênero: conceitos e termos. Brasília, 2012. $41 \mathrm{p}$.

MACKEY, Alison; GASS, Susan. Second Language Research: methodology and design. Routledge, Nova York, v. 2. p. 43-99, 2005.

MARANHÃO, Maximiliano Salvadori. TIC Cultura: Pesquisa sobre o uso das tecnologias de informação e comunicação nos equipamentos culturais brasileiros. Comitê Gestor da Internet no Brasil, São Paulo, 2019. Disponível em: https://www.cetic.br/media/docs/

publicacoes/1/tic cultura 2018 livro eletronico.pdf. Acesso em: 5 nov. 2020.

MARINS, Eliézer; SHIBATTA, Luis. O impacto do Coronavírus nas pequenas e médias empresas. RH para você. Grupo Top RH: São Paulo 2020. Disponível em: https://rhpravoce.

com.br/posts/o-impacto-do-coronavirus-nas-pequenas-e-medias-empresas. Acesso em: 10 nov. 2020.

MATO GROSSO DO SUL. Fundação de Cultura lança edital emergencial para auxiliar artistas durante período da pandemia do coronavírus. Governo do Estado de Mato Grosso do Sul. Fundação de Cultura de Mato Grosso do Sul (FCMS). Campo Grande, 2020. Disponível em: https://www.fundacaodecultura.ms.gov.br/fundacao-de-cultura-lanca-edital-emergencial-para-auxiliarartistas-durante-periodo-da-pandemia-do-coronavirus. Acesso em: 10 dez. 2020. 
MATO GROSSO DO SUL. Boletim epidemiológico do coronavírus: casos em Mato Grosso do Sul, do dia 18 de dezembro de 2020. Governo do Estado de Mato Grosso do Sul. Secretaria de Estado de Saúde. Diretoria Geral da Vigilância em Saúde, 2020a. Disponível em: https://www.vs.saude.ms.gov.br/wpcontent/uploads/2020/12/Boletim-Epidemiologico-COVID-19-2020.12.18.pdf. Acesso em: 18 dez. 2020.

MATO GROSSO DO SUL. Decreto n. ${ }^{\circ}$ 14.189, de 15 de março de 2020. Diário Oficial de Campo Grande. Campo Grande, 16 mar. 2020b. Disponível em: http://www.campogrande.ms.

gov.br/sesau/downloads/decreto-n-14-189-de-15-de-marco-de-2020-covid-19-campo-grande-ms/. Acesso em: 10 nov. 2020.

MILLER, Jussara. O corpo presente: uma experiência sobre dança-educação. ETD-Educação Temática Digital, Campinas, v. 16, n. 1, p. 100-114, 2014.

MOREIRA, Rui. Balé clássico: um dos métodos de formação e preparo de artistas de dança expressiva cênica na contemporaneidade. In: Instituto Festival de Dança de Joinville (orgs.). A Dança Clássica: dobras e extensões. Nova Letra, Joinville: p. 85-90, 2014.

NISHIURA, Hiroshi; KOBAYASHI, Tetsuro; MIYAMA, Takeshi; SUZUKI, Ayako; JUNG, Sung-Mok; HAYASHI, Katsuma; LINTON, Natalie. Estimation of the asymptomatic ratio of novel coronavirus infections (COVID-19). International journal of infectious diseases. Hokkaido, v. 94, p. 154, 2020.

PASINI, Carlos Giovani Delevati; CARVALHO, Élvio de; ALMEIDA, Lucy Hellen Coutinho. A educação híbrida em tempos de pandemia: algumas considerações. Fundação de Amparo à Pesquisa do Estado do Rio Grande do Sul (FAPERGS). Ministério da Educação. Universidade Federal de Santa Maria (UFSM), Santa Maria, 2020.

SEBRAE, Serviço Brasileiro de Apoio às Micro e Pequenas Empresas, O impacto da pandemia de coronavírus nos pequenos negócios. 3. ed., 2020. Disponível em: https://www.sebrae.com.br/sites/PortalSebrae. Acesso em: 10 nov. 2020.

SILVA, Luis Henrique; OLIVEIRA, Anna Augusta Sampaio. Contribuições do projeto piloto à coleta de dados em pesquisas na área de educação. Revista Ibero-Americana de Estudos em Educação, São Paulo. v. 10, n. 1, p. 225-245, 2015.

SIQUEIRA, Fanny Cacilie Gauna de; MANFROI, Miraira Noal; ROSA, Marcelo Victor da; MARINHO, Alcyane, Conceito-ação da dança contemporânea. Pensar a Prática, Goiânia, v. 19, n. 2, 2016.

SOUZA, Kellcia Rezende; KERBAUY, Maria Teresa Miceli. Abordagem quanti-qualitativa: superação da dicotoamia quantitativa-qualitativa na pesquisa em educação. Educação e Filosofia. Uberlândia, v. 31 n. 61, 2017.

TERRA, Ana. Onde se produz o artista da dança. Algumas perguntas sobre dança e educação. Nova Letra, Joinville, v. 1, p. 67-76, 2009.

WORLD HEALTH ORGANIZATION (WHO). Director-General 's remarks at the media briefing on 2019-nCoV on 11 February 2020. Genebra, 11 fev. 2020. Disponível em https://www.who.int/dg/speeches/detail/who-director-general-s-remarks-at-the-media-briefing-on-2019ncov-on-11-february-2020. Acesso em: 20 de outubro de 2020.

WORLD HEALTH ORGANIZATION (WHO). IHR procedures concerning public health emergencies of international concern (PHEIC). Strengthening health security by implementing the International Health Regulations. International Health Regulations. IHR procedures and implementation, 2005. Disponível em: http://www.who.int/ihr/procedures/pheic/en/. Acesso em: 20 out. 2020. 
ZIKAN, Fernando Eduardo; MUTUANO, Bruno; FERREIRA, Faysa; MAGALHÃES, Fernanda; SANTOS, Greyce; OLIVEIRA, Yasmin. Saúde e Dança: alternativas virtuais de orientações em saúde - uma ação de extensão adaptada durante a pandemia de Covid-19. Raízes e Rumos, Rio de Janeiro. v. 8, n. 2, p. 210-219, 2020.

\section{NOTAS DE AUTOR}

\section{AGRADECIMENTOS}

Não se aplica.

CONTRIBUIÇÃO DE AUTORIA - não se aplica

\section{FINANCIAMENTO}

"O presente trabalho foi realizado com apoio da Coordenação de Aperfeiçoamento de Pessoal de Nível Superior - Brasil (CAPES) - Código de Financiamento 001”.

CONSENTIMENTO DE USO DE IMAGEM - Não se aplica

APROVAÇÃO DE COMITÊ DE ÉTICA EM PESQUISA - Não se aplica.

CONFLITO DE INTERESSES - Não se aplica.

\section{LICENÇA DE USO}

Os autores cedem à Motrivivência - ISSN 2175-8042 os direitos exclusivos de primeira publicação, com o trabalho simultaneamente licenciado sob a Licença Creative Commons Attribution Non-Comercial ShareAlike (CC BY-NC SA) 4.0 International. Esta licença permite que terceiros remixem, adaptem e criem a partir do trabalho publicado, desde que para fins não comerciais, atribuindo o devido crédito de autoria e publicação inicial neste periódico desde que adotem a mesma licença, compartilhar igual. Os autores têm autorização para assumir contratos adicionais separadamente, para distribuição não exclusiva da versão do trabalho publicada neste periódico (ex.: publicar em repositório institucional, em site pessoal, publicar uma tradução, ou como capítulo de livro), com reconhecimento de autoria e publicação inicial neste periódico, desde que para fins não comerciais e compartilhar com a mesma licença.

\section{PUBLISHER}

Universidade Federal de Santa Catarina. Programa de Pós-Graduação em Educação Física. LaboMídia - Laboratório e Observatório da Mídia Esportiva. Publicado no Portal de Periódicos UFSC. As ideias expressadas neste artigo são de responsabilidade de seus autores, não representando, necessariamente, a opinião dos editores ou da universidade.

\section{EDITORES}

Mauricio Roberto da Silva, Giovani De Lorenzi Pires, Rogério Santos Pereira.

\section{EDITOR DE SEÇÃO}

Juliano Silveira.

\section{REVISÃO DO MANUSCRITO E METADADOS}

João Caetano Prates Rocha; Keli Barreto Santos.

\section{HISTÓRICO}

Recebido em: 02 de março de 2021.

Aprovado em: 13 de julho de 2021. 